\title{
Bioatividade de extratos hidroalcoólicos de Cymbopogon citratus (DC.) Stapf. sobre picão-preto (Bidens pilosa L.) e alface (Lactuca sativa L.)
}

\author{
LOUSADA, L.L. ${ }^{1 *}$; LEMOS, G.C.S. ${ }^{1}$; FREITAS, S.P. ${ }^{1}$; DAHER, R.F. ${ }^{2}$ ESTEVES, B.S. ${ }^{2}$ \\ ${ }^{1}$ Laboratório de Fitotecnia; 'Laboratório de Engenharia Agrícola, Universidade Estadual do Norte Fluminense \\ (UENF), Avenida Alberto Lamego, 2000, Parque Califórnia, CEP: 28013-602, Campos dos Goytacazes-Brasil \\ *delimalousada@yahoo.com.br
}

\begin{abstract}
RESUMO: Este trabalho visou avaliar a bioatividade de extratos hidroalcoólicos de capim-limão sobre germinação e crescimento inicial da planta daninha picão-preto (Bidens pilosa L.) e da planta teste alface (Lactuca sativa L.). A partir de maceração hidroalcoólica de folhas secas e rasuradas $(127,46 \mathrm{~g})$ de capim-limão em $1 \mathrm{~L}$ de álcool de cereais $(70 \%)$, foram preparados os tratamentos como extratos hidroalcoólicos $(\mathrm{HA})$ pela diluição $(\mathrm{v} / \mathrm{v})$ do macerado filtrado em água deionizada na proporção 1:1 (HA1:1) e 1:2 (HA1:2); dos quais foram obtidos os respectivos extratos secos (ES), a partir da evaporação da fase líquida de duas alíquotas de $50 \mathrm{~mL}$ de cada extrato HA, que após re-suspendidas em igual volume de água, sendo uma autoclavada (1 atm por 15 minutos), resultando nos extratos secos de HA1:1 e HA1:2 autoclavados (ES1:1A e ES1:2A) e nos extratos secos não autoclavados (ES1:1 e ES1:2); e água (AG) como controle. No primeiro dia dos bioensaios, foram aplicados $2 \mathrm{~mL}$ dos tratamentos, em DIC, com cinco repetições. Avaliou-se a porcentagem de germinação (G\%), Índice de Velocidade de Germinação (IVG), altura da parte aérea (AA) e comprimento de radícula (CR) de aquênios (25) de picão-preto e de alface distribuídos em placas de Petri e mantidos em câmara de germinação (B.O.D.) por duas semanas. Os extratos HA1:1 e HA1:2 inibiram a G\%, AA e CR das duas espécies. Todos os extratos secos reduziram a G\%, IVG e o CR da alface. Para o picão preto, apenas o extrato ES1:1 reduziu a G\% e o IVG foi reduzido por todos os extratos, a exceção do ES1:1A, mas nenhum extrato influenciou o crescimento inicial desta espécie.
\end{abstract}

Palavras-chave: alelopatia, extrato seco, planta daninha, planta medicinal

ABSTRACT: Bioactivity of hydroalcoholic extracts of Cymbopogon citratus (DC.) Stapf. on germination and early growth of beggartick (Bidens pilosa L.) and lettuce (Lactuca sativa L.). This study aimed to evaluate the bioactivity of hydroalcoholic extract of lemongrass on the germination and early growth of the weed plant beggartick (Bidens pilosa L.) and the test plant lettuce (Lactuca sativa L.). From the hydroalcoholic maceration of dried and cut leaves of lemon grass $(127.46 \mathrm{~g})$ in $1 \mathrm{~L}$ grain alcohol $(70 \%)$, the following treatments were prepared, hydro-alcoholic (HA) extracts by diluting (v/v) the macerate in deionized water at 1:1 (HA1:1) and 1:2 (HA1:2) proportions, obtaining the respective dried extracts (DE) from the evaporation of the liquid phase of two 50-mL aliquots of each HA extract; after resuspension in the same water volume, one aliquot was autoclaved (1 atm for 15 minutes) resulting in HA1:1 and HA1:2 dried autoclaved extracts (DE1:1A and DE1:2A) and in dried non-autoclaved extracts (ES1:1 and ES1:2), and water as control. On the first day of bioassays, $2 \mathrm{~mL}$ of treatments were applied, in completely randomized design, with 5 replicates. Germination percentage (G\%), Germination Speed Index (GSI), shoot height (SH) and radicle length (RL) of achenes (25) of beggartick and lettuce were evaluated after having been distributed in Petri dishes and kept in a germination chamber (B.O.D.) for two weeks. HA1:1 and HA1:2 extracts inhibited $\mathrm{G} \%$, SH and RL of both species. All dried extracts reduced G\%, GSI and CR of lettuce. For beggartick, only ES1:1 extract reduced G\% while GSI was reduced in all extracts, except ES1:1A, but no extract influenced the early growth of this species.

Key words: allelopathy, dry extract, weed, medicinal plant

Recebido para publicação em 15/07/2010

Aceito para publicação em 29/12/2011

Rev. Bras. PI. Med., Botucatu, v.14, n.2, p.282-286, 2012. 


\section{INTRODUÇÃO}

A espécie picão-preto (Bidens pilosa L.), originária da América Tropical, é uma espécie herbácea e ereta, autógama com taxa de $9 \%$ de fecundação cruzada (Vidal et al., 2007), propagandose apenas por sementes, com ciclo anual e curto bastante para completar até três gerações por ano, sendo encontrada em todo território brasileiro (Lorenzi, 2000), e apontada como uma das piores plantas daninhas de culturas anuais em mais de 40 países (Kissmann \& Groth, 1992), devido à alta competitividade conferida pelo desenvolvimento em altas densidades (Akobundu, 1987).

O controle químico de picão preto é o mais utilizado, apesar da alta resistência da espécie a diversos herbicidas (Kissmann, 1997; Vidal et al., 2006), porque o controle mecânico favorece a sua rápida re-infestação propiciada pela elevada eficiência de formação de banco de sementes no solo (Ferreira et al., 2007).

Entre as estratégias de prospecção de bioherbicidas ou práticas de manejo que reduzam a utilização de produtos químicos, destacam-se os estudos fundamentados na alelopatia (BalbinotJunior, 2004). Esta se caracteriza pela interação positiva ou negativa de espécies vegetais ou microorganismos sobre o crescimento de sistemas biológicos (Pinto, 2002), a qual é atribuída aos aleloquimicos, isto é, compostos biossíntetizados via metabolismo secundário e liberados (volatilização, exsudação radicular, lixiviação ou decomposição de resíduos) no ambiente, a partir de tecido vivo ou morto de qualquer parte do vegetal (Souza Filho \& Alves, 2002).

Considerando que a atividade biológica de plantas medicinais é atribuída à presença de princípios ativos de caráter terapêutico em pelo menos um dos órgãos de qualquer vegetal (Veiga Junior et al., 2005), os quais, assim como os aleloquímicos, são oriundos do metabolismo secundário vegetal (Simões et al., 2001), é comum a associação do potencial alelopático vegetal às plantas medicinais (Souza et al., 2005; Magiero et al., 2009).

Saito (2004) comenta que plantas medicinais com princípio ativo da categoria dos óleos voláteis são promissoras como bioherbicidas, entre as quais, cita-se o capim-limão (Cymbopogon citratus), cuja atividade alelopática foi demonstrada com extratos aquosos (Dudai et al., 1999; Vieira \& Soares, 2000; Piccolo et al., 2007; Lima et al., 2009) e com óleos essenciais (Alves et al., 2004), em biotestes laboratoriais. Estes testes são mais indicados devido à complexidade das inter-relações planta e ambiente que podem interferir na atividade dos metabólitos secundários, e embora não revelem os compostos ou fenômenos envolvidos, podem detectar a interferência no crescimento e no desenvolvimento das espécies testadas, contribuindo com a indicação de possíveis fontes de novos compostos com bioatividade potencial (Mairesse et al., 2007).

A compreensão da natureza química dos aleloquímicos depende da forma de obtenção dos extratos, preferencialmente polares, que melhor caracterizam as condições naturais, seguindo-se até o isolamento e a identificação da(s) molécula(s) bioativa(s) que caracterizem a alelopatia (Souza Filho \& Alves, 2002).

Este trabalho tem por objetivo avaliar a bioatividade de extratos hidroalcoólicos de capimlimão (C. citratus) sobre a germinação e o crescimento inicial da planta daninha picão-preto (B. pilosa) e da planta teste alface (L. sativa).

\section{MATERIAL E MÉTODO}

\section{Material vegetal}

Aquênios de picão-preto, coletados no campus da UENF, foram acondicionados em sacos de papel e mantidos em geladeira até a realização dos biotestes.

A planta-teste foi a alface (Lactuca sativa L.), cultivar "Babá de Verão" (Manteiga - Toop Seed(B), cujas sementes foram obtidas no comércio local.

Folhas de capim-limão foram colhidas, pela manhã, de uma única touceira cultivada na Unidade de Apoio à Pesquisa da UENF, pesadas e submetidas à secagem em estufa com ventilação forçada de ar, a $40^{\circ} \mathrm{C}$, até massa constante, para obtenção dos extratos.

\section{Obtenção dos extratos}

A partir de maceração hidroalcoólica de folhas secas e rasuradas de capim-limão $(127,46 \mathrm{~g})$ em $1 \mathrm{~L}$ de álcool de cereais (70\%), na ausência de luz, por sete dias, e filtração em papel de filtro tipo K, foram preparados os tratamentos na forma de extratos hidroalcoólicos (HA) pela diluição, volume por volume, do filtrado do macerado em água deionizada nas proporções 1:1 (HA1:1) e 1:2 (HA1:2); e destes foram obtidos os respectivos extratos secos (ES), a partir da evaporação da fase líquida de 2 alíquotas de $50 \mathrm{~mL}$ de cada $\mathrm{HA}$, que após ressuspendidas em igual volume de água, sendo uma esterilizada em autoclave a $1 \mathrm{~atm}$, durante 15 minutos, resultando nos extratos secos de HA1:1 e HA1:2 autoclavados (ES1:1A e ES1:2A) e outra não autoclavada resultando nos extratos secos não autoclavados (ES1:1 e ES1:2); sendo o controle com água (AG). Os extratos foram analisados quanto ao $\mathrm{pH}$, com pHmetro de bancada (Micronal - B474) e à condutividade elétrica (CE), determinada com condutivímetro (Hanna HI 8820N).

Rev. Bras. Pl. Med., Botucatu, v.14, n.2, p.282-286, 2012. 


\section{Bioensaios de alelopatia}

Os bioensaios foram conduzidos no Setor de Plantas Daninhas e Medicinais, Laboratório de Fitotecnia, da Universidade Estadual do Norte Fluminense (UENF), em Campos dos Goytacazes, RJ.

As unidades experimentais constituíram-se de placas de Petri, com $9 \mathrm{~cm}$ de diâmetro, forradas com papel de filtro tipo $\mathrm{K}$, onde foram dispostos, aleatoriamente, 25 aquênios por espécies por placa, com cinco repetições por tratamento, em delineamento inteiramente casualizado (DIC). As placas foram mantidas em câmara de germinação (B.O.D.) com fotoperíodo de 8/16 horas (luz/escuro) e temperatura de $20^{\circ} \mathrm{C}$ para a alface (Brasil, 1992) e, fotoperíodo de 10/14 horas e temperatura de 27 e $25^{\circ} \mathrm{C}$ (dia e noite) para o picão-preto (Rios et al., 1989)

Apenas no primeiro dia, foram aplicados 2 $\mathrm{mL}$ dos tratamentos constituídos pelos extratos hidroalcoólico:água 1:1 (HA1:1) e 1:2 (HA1:2); seus respectivos extratos secos autoclavados (ES1:1A e ES1:2A) e não autoclavados (ES1:1 e ES1:2); e controle com água ( $A G)$, mantendo-se a umidade com água sempre que necessário, durante 15 dias.

A bioatividade dos extratos foi avaliada em função da capacidade de germinação, determinada pela porcentagem de germinação (G\%) e pelo Índice de Velocidade de Germinação (IVG), e em função do vigor das sementes através da observação do crescimento inicial das espécies, determinado pela altura da parte aérea (AA) e pelo comprimento de radícula $(C R)$ das plântulas.

Considerou-se como germinadas as sementes que apresentaram protusão de radícula de pelo menos $2 \mathrm{~mm}$, calculando-se a porcentagem (G\%) de acordo com as Regras para Análise de Sementes (Brasil, 1992), segundo a equação 01:

$$
\mathrm{G}=\left(\mathrm{N}_{1} / \mathrm{A}+\mathrm{N}_{2} / \mathrm{A}+\ldots+\mathrm{N}_{\mathrm{n}} / \mathrm{A}\right) \times 100
$$

onde: $\mathrm{G}=$ porcentagem de germinação (\%); $\mathrm{N}$ = número total de sementes germinadas; $A=$ número total de sementes colocadas para germinar e $n=$ número de dias.

O Índice de Velocidade de Germinação (IVG) foi calculado de acordo com a fórmula proposta por Maguire (1962), o qual estima o número médio de sementes normais por dia (Teixeira et al., 2004), segundo a equação 02:

$$
I V G=G_{1} / N_{1}+G_{2} / N_{2}+\ldots+G_{n} / N_{n}
$$

onde: $I V G=$ índice de velocidade de germinação; $G$ = número de plântulas normais computadas na primeira contagem, na segunda contagem e na última contagem; $\mathrm{N}$ = número de dias da semeadura à primeira, à segunda e à última contagem e $n=$ número de dias
A altura da parte aérea (AA) e o comprimento de radícula $(C R)$ foram medidos com régua de precisão de $\mathrm{mm}$ com auxílio de lupa.

Os resultados foram submetidos à análise de variância (ANOVA), comparando-se as médias pelo teste de Tukey, em nível de $5 \%$ de probabilidade.

\section{RESULTADO E DISCUSSÃO}

A germinação da alface foi reduzida por todos os extratos, HA1:1 (0\%), HA1:2 (0\%), ES1:1A (69\%), ES1:2 (81\%), ES1:1 (78\%), ES1:2A (77\%) em relação ao controle AG (100\%), e o IVG também foi reduzido por todos os tratamentos. A germinação do picãopreto foi inibida pelos extratos HA1:1 (0\%) e HA1:2 $(0 \%)$, e reduzida pelo $E S 1: 1(70,4 \%)$ em relação ao controle AG $(84,0 \%)$, enquanto o IVG foi reduzido por todos os tratamentos, a exceção do $\operatorname{ES1:1A}(4,68)$ (Tabela 1).

Embora ambas as espécies sejam da família Asteraceae, a alface apresenta semente praticamente nua, a que se atribui sua maior sensibilidade, ao contrário do picão preto, cujo tegumento mais espesso pode constituir uma barreira física á penetração dos extratos, e assim menor sensibilidade aos extratos, aliado à alta diversidade genética da espécie (Vidal et al., 2007) e à dormência de sementes (Kissmann, 1997).

A fase de germinação é menos sensível à ação de aleloquímicos, embora o padrão de germinação possa ser alterado em função de diferenças na velocidade e na sincronia da germinação

TABELA 1. Germinação (G\%) e Índice de Velocidade de Germinação (IVG) de alface e de picão-preto sob tratamentos com extratos hidroalcoólicos (HA1:1 e HA1:2); seus respectivos extratos secos não autoclavados (ES1:1 e ES1:2) e autoclavados (ES1:1A e ES1:2A); e controle com água ( $A G)$.

\begin{tabular}{lcccc}
\hline \multirow{2}{*}{ Tratamentos } & \multicolumn{2}{c}{ Alface } & \multicolumn{3}{c}{ Picão Preto } \\
\cline { 2 - 5 } & $\mathbf{G} \%$ & \multicolumn{1}{c}{ IVG } & \multicolumn{1}{c}{ G\% } & NG \\
\hline HA1:1 & 0,00 & 0,00 & 0,00 & 0,00 \\
HA1:2 & 0,00 & 0,00 & 0,00 & 0,00 \\
ES1:1 & $78,00^{\mathrm{B}}$ & $3,00^{\mathrm{C}}$ & $70,40^{\mathrm{C}}$ & $2,44^{\mathrm{B}}$ \\
ES1:2 & $81,00^{\mathrm{B}}$ & $4,15^{\mathrm{B}}$ & $74,40^{\mathrm{BC}}$ & $2,30^{\mathrm{B}}$ \\
ES1:1A & $69,00^{\mathrm{C}}$ & $2,85^{\mathrm{C}}$ & $87,20^{\mathrm{A}}$ & $4,68^{\mathrm{A}}$ \\
ES1:2A & $77,00^{\mathrm{BC}}$ & $3,15^{\mathrm{C}}$ & $72,80^{\mathrm{BC}}$ & $2,75^{\mathrm{B}}$ \\
AG & $100,00^{\mathrm{A}}$ & $12,20^{\mathrm{A}}$ & $84,00^{\mathrm{AB}}$ & $4,51^{\mathrm{A}}$ \\
\hline CV\% & 7,97 & 11,13 & 11,27 & 23,34 \\
\hline
\end{tabular}

CV\%: coeficiente de variação. Médias seguidas de letras iguais na mesma coluna não diferiram significativamente entre si, pelo teste de Tukey (5\%) 
de sementes submetidas a tais compostos (Santana et al., 2006). Ferreira et al. (2007) verificaram que a velocidade de germinação das sementes de picãopreto foi reduzida pelo extrato etanólico de $E$. citriodora, enquanto Teixeira et al. (2004) observaram o mesmo padrão de redução da germinação de picãopreto e de alface por extratos aquosos de mucuna preta rajada, guandu comum e guandu-anão, o que não se repetiu para o IVG, uma vez que a alface foi mais sensível do que o picão-preto, conforme também observado no presente estudo.

A fase de crescimento é mais sensível aos aleloquímicos do que a germinação, podendo surgir plântulas anormais, necroses radiculares ou alterações no crescimento (Ferreira \& Borghetti, 2004).

O crescimento inicial das plântulas de ambas as espécies, assim como a germinação, também foi totalmente inibido pelos extratos HA1:1 e HA1:2. Para a alface, a altura da parte aérea das plântulas sob ES1:2 $(2,15 \mathrm{~cm})$ foi maior do que sob ES1:1 (1,55 $\mathrm{cm}$ ), embora ambos não tenham diferido dos demais tratamentos, enquanto o comprimento de radícula foi reduzido por todos os tratamentos em relação ao controle AG. Para o picão-preto, a altura da parte aérea das plântulas não foi influenciada pelos extratos secos autoclavados ou não autoclavados em relação ao controle, mas o comprimento de radícula foi reduzido pelos ES1:1A $(4,72 \mathrm{~cm})$ e ES1:1 $(4,30 \mathrm{~cm})$ em relação ao ES1:2A $(6,58 \mathrm{~cm})$ (Tabela 2). Não ocorreram quaisquer alterações ou necroses das plântulas em ambas as espécies. Por outro lado, Ferreira et al. (2007) observaram que o comprimento radicular de alface e de picão-preto não diferiu entre os extratos etanólicos de Eucalyptus citriodora e Pinus elliottii.

As diferenças de respostas da capacidade de germinação (G\% e IVG) da alface e do picão-preto podem indicar a presença de diferentes compostos agindo especificamente em função de características genéticas das espécies testadas, enquanto a resposta mais efetiva dos extratos secos sobre o comprimento de radículas do que sobre a altura de parte aérea de ambas as espécies, indicam a possibilidade de composto(s) agindo em nesta etapa de desenvolvimento.

A desinfestação de sementes e esterilização de extratos são recomendados para evitar riscos de contaminação microbiológica em biotestes de laboratório, não sendo comuns em trabalhos de alelopatia para interação planta-planta. Contudo, a forma de obtenção e preparo, o método de aplicação e a concentração de extratos vegetais podem influir nas respostas da bioatividade, devido ao risco da instabilidade dos princípios ativos (Mano, 2006).

Como o $\mathrm{pH}$ e a $\mathrm{CE}$ dos extratos estavam dentro dos limites aceitáveis (Tabela 3), a maior eficácia dos extratos HA pode estar relacionada à
TABELA 2. Altura da parte aérea (AA) e comprimento da raiz $(C R)$ de alface e de picão-preto sob tratamentos extratos hidroalcoólicos (HA1:1 e HA1:2); seus respectivos extratos secos não autoclavados (ES1:1 e ES1:2) e autoclavados (ES1:1A e ES1:2A); e controle com água (AG).

\begin{tabular}{lllll}
\hline \multirow{2}{*}{ Tratamentos } & \multicolumn{2}{c}{ Alface } & \multicolumn{2}{c}{ Picão Preto } \\
\cline { 2 - 5 } & AA $(\mathbf{c m})$ & $\mathbf{C R}(\mathbf{c m})$ & \multicolumn{1}{c}{ AA (cm) } & $\mathbf{C R}(\mathbf{c m})$ \\
\hline HA1:1 & 0,00 & 0,00 & 0,00 & 0,00 \\
HA1:2 & 0,00 & 0,00 & 0,00 & 0,00 \\
ES1:1 & $1,55^{\mathrm{B}}$ & $3,83^{\mathrm{B}}$ & $2,82^{\mathrm{A}}$ & $4,30^{\mathrm{B}}$ \\
ES1:2 & $2,15^{\mathrm{A}}$ & $3,85^{\mathrm{B}}$ & $2,54^{\mathrm{A}}$ & $5,14^{\mathrm{AB}}$ \\
ES1:1A & $1,92^{\mathrm{AB}}$ & $4,20^{\mathrm{B}}$ & $2,52^{\mathrm{A}}$ & $4,72^{\mathrm{B}}$ \\
ES1:2A & $1,88^{\mathrm{AB}}$ & $3,65^{\mathrm{B}}$ & $3,12^{\mathrm{A}}$ & $6,58^{\mathrm{A}}$ \\
AG & $1,89^{\mathrm{AB}}$ & $5,00^{\mathrm{A}}$ & $2,64^{\mathrm{A}}$ & $5,54^{\mathrm{AB}}$ \\
\hline CV\% & 12,22 & 12,64 & 17,01 & 22,74 \\
\hline
\end{tabular}

CV\%: coeficiente de variação. Médias seguidas de letras iguais na mesma coluna não diferiram significativamente entre si, pelo teste de Tukey $(5 \%)$

presença do álcool, à sinergismos, ou à alteração molecular e, ou inativação de compostos químicos durante a preparação dos extratos secos (ES). Por outro lado, Oliveira et al. (2002) atribuiram à maior capacidade extrativa do etanol, em quantidade ou em especificidade de substâncias bioativas, o maior poder inibitório do extrato etanólico de Hymenaea stigonocarpa sobre $\mathrm{G} \%$ de alface.

Trabalhos de alelopatia com capim-limão demonstraram que o extrato aquoso reduziu a germinação, o comprimento da radícula e a velocidade da germinação das sementes de guanxuma (Sida rhombifolia L.) (Piccolo et al., 2007), e diferentes concentrações do óleo essencial inibiram a germinação de alface in vitro (Alves et al., 2004), indicando a presença de diferentes fitocomplexo(s) ou composto(s) ativo(s) polar(es) e apolar(es) na espécie.

Testes de germinação são ferramentas importantes para identificação de plantas

TABELA 3. Parâmetros químicos dos extratos.

\begin{tabular}{llc}
\hline Extratos & $\mathbf{p H}$ & Condutividade $(\mu \mathrm{s} / \mathrm{cm})$ \\
\hline HA1:1 & 5,61 & 630 \\
HA1:2 & 5,23 & 620 \\
ES1:1 & 4,64 & 1630 \\
ES1:2 & 4,64 & 1370 \\
ES1:1A & 4,64 & 1820 \\
ES1:2A & 4,64 & 1560 \\
\hline
\end{tabular}


potencialmente bioativas por serem simples e de rápida interpretação (Souza et al., 2007), contribuindo com subsídios para novas estratégias que permitam avançar em estudos fundamentados em alelopatia.

\section{CONCLUSÃO}

Os extratos HA1:1 e HA1:2 de C. citratus inibiram totalmente a germinação e o crescimento inicial da alface e do picão preto.

Todos os extratos secos reduziram a germinação, o Índice de Velocidade de Germinação e o crescimento radicular inicial da alface.

Para o picão preto, a germinação foi reduzida apenas pelo extrato ES1:1 e todos os extratos, a exceção do ES1:1A, reduziram o IVG, mas nenhum extrato influenciou o crescimento inicial da espécie.

\section{AGRADECIMENTO}

A FAPERJ pelo apoio e suporte financeiro e à UENF pela concessão da bolsa.

\section{REFERÊNCIA}

AKOBUNDU, I. O. Weed science in the tropics: principles and practices. Norwich: J. Wiley, 1987. 522p. ALVES, M.C.S.; FILHO, S.M.; INNECCO, R. Alelopatia de extratos voláteis na germinação de sementes e no comprimento da raiz de alface. Pesquisa Agropecuária Brasileira, v.39, n.11, p.1083-6, 2004.

BALBINOT-JUNIOR, A.A. Manejo das plantas daninhas pela alelopatia. Agropecuária Catarinense, v.17, n.1, p.61-4, 2004. BRASIL. Ministério da Agricultura e Reforma Agrária. Regras para análise de sementes. Brasília, 1992. 365p. DUDAI, N. et al. Essential oils as allelochemicals and their potencial use as herbicides. Journal of Chemical Ecology, v.25, n.5, p.1079-89, 1999.

FERREIRA, A.G.; BORGHETTI, F. Germinação: do básico ao aplicado. Porto Alegre: Artmed. 2004. 323p

FERREIRA, M.C.; SOUZA, J.R.P.; FARIA, T.J. Potenciação alelopática de extratos vegetais na germinação e no crescimento inicial de picão-preto e alface. Ciência Agrotecnica, v.31, n.4, p.1054-60, 2007.

KISSMANN, G.K. Plantas daninhas e nocivas. 2.ed. São Bernardo do Campo: BASF Brasileira, 1997. 825p.

KISSMANN, K.G.; GROTH, D. Plantas infestantes e nocivas. São Paulo: BASF Brasileira, 1992. 798p.

LIMA, G.P. et al. Alelopatia de capim-limão (Cymbopogon citratus) e sabugueiro (Sambucus australis) na germinação e desenvolvimento inicial de corda-de-viola (Ipomoea grandifolia). Revista Ciências Agrárias e Engenharias, v.15, n.2, p.121-7, 2009.

LORENZI, H. Plantas daninhas do Brasil: terrestres, aquáticas parasitas e tóxicas. 3.ed. Nova Odessa: Editora Plantarum, 2000. 608p.

MAGIERO, E.C. et al. Efeito alelopático de Artemisia annua L. na germinação e desenvolvimento inicial de plântulas de alface (Lactuca sativa L.) e leiteiro (Euphorbia heterophylla L.). Revista Brasileira de Plantas Medicinais, v.11, n.3, p.317-24, 2009.

MAGUIRE, J.D. Speed of germination-aid in selection and evaluation for seedling emergence and vigor. Crop Science, v.2, n.1, p.176-99, 1962.

MAIRESSE, L.A.S. et al. Bioatividade de extratos vegetais sobre alface (Lactuca sativa L.). Revista da FZVA, v.14, n.2, p.1-12, 2007.

MANO, A.R.O. Efeito alelopático do extrato aquoso de sementes de cumaru (Amburana cearensis S.) sobre a germinação de sementes, desenvolvimento e crescimento de plântulas de alface, picão-preto e carrapicho. 2006. 102p. Dissertação (Mestrado) Universidade Federal do Ceará, Fortaleza.

OLIVEIRA, N.S. et al. Efeitos alelopáticos dos extratos aquoso e etanólico de jatobá do cerrado. Unimontes Científica, v.4, n.2, p.1-12, 2002.

PICCOLO, G. et al. Efeito alelopático de capim limão e sabugueiro sobre a germinação de guanxuma. Semina: Ciências Agrárias, v.28, n.3, p.381-6, 2007.

PINTO, A.C. Produtos naturais: atualidade, desafios e perspectivas. Química Nova, v.25, supl.1, p.45-61, 2002. RIOS, A.; MANTOVANI, E.; SEDIYAMA, C. Efeito da temperatura na germinação de frutos polimórficos de Bidens pilosa L. Malezas, v.17, n.2, p.20-6, 1989.

SAITO, L.M. As plantas praguicidas: alternativa para o controle de pragas da agricultura. Jaguariúna: Embrapa Meio Ambiente, 2004. 4p.

SANTANA, D.G. et al. Germination meansurements to evaluate allelopathic interactions. Allelopathy Journal, v.17, p.43-52, 2006.

SIMÕES, CM.O. et al. Farmacognosia: da planta ao medicamento. Florianópolis: Editora Universidade Federal de Santa Catarina 2001. 1104p.

SOUZA FILHO, A.P.; ALVES, S.M. Alelopatia: princípios básicos e aspectos gerais. Belém: Embrapa Amazônica Oriental, 2002. 260p.

SOUZA, S.A.M. et al. Efeito de extratos aquosos de plantas medicinais nativas do Rio Grande do Sul sobre a germinação de sementes de alface. Publicatio UEPG: Ciências Biológicas e da Saúde, v.11, n.3/4, p.29-38, 2005.

SOUZA, C.S.M. et al. Alelopatia do extrato aquoso de folhas de aroeira na germinação de sementes de alface. Revista Verde, v.2, n.2, p.96-100, 2007.

TEIXEIRA, C.M.; ARAÚJO, J.B.S.; CARVALHO G.J. Potencial alelopático de plantas de cobertura no controle de picão-preto (Bidens pilosa.). Ciência e Agrotecnologia, v.28, n.3, p.691-5, 2004.

VEIGAJUNIOR, V.F.; PINTO, A.C.; MACIEL, M.A.M. Plantas medicinais: cura segura? Química Nova, v.28, n.3, p.51928, 2005.

VIDAL, R.A. et al. Relação entre distância geográfica e variabilidade genética de uma população de Bidens spp. com resistência aos herbicidas inibidores de ALS. Planta Daninha, v.24, n.1, p.149-55, 2006.

VIDAL, R.A. et al. Análise genética de genótipos de Bidens pilosa através da técnica RAPD. Scientia Agraria, v.8, n.4, p.399-403, 2007.

VIEIRA, T.R.; SOARES, G.L.G. Inibição da germinação e do crescimento radicular de alface (Cv. "Grand Rapids") por extratos aquosos de cinco espécies de Gleicheniaceae. Floresta e Ambiente, v.7, n.1, p.180-97, 2000. 